\title{
On the Stability of a New Pexider-Type Functional Equation
}

\author{
Kil-Woung Jun, ${ }^{1,2}$ Yang-Hi Lee, ${ }^{3}$ and Juri Lee ${ }^{2}$ \\ ${ }^{1}$ National Institute for Mathematical Sciences, Daejeon 305-340, South Korea \\ ${ }^{2}$ Department of Mathematics, Chungnam National University, Daejeon 305-764, South Korea \\ ${ }^{3}$ Department of Mathematics Education, Gongju National University of Education, \\ Gongju 314-711, South Korea
}

Correspondence should be addressed to Yang-Hi Lee, yanghi2@hanmail.net

Received 1 October 2007; Accepted 31 January 2008

Recommended by Patricia Wong

We establish the generalized Hyers-Ulam stability of a Pexider-type functonal equation $f_{1}(x+y+$ $z)+f_{2}(x-y)+f_{3}(x-z)-f_{4}(x-y-z)-f_{5}(x+y)-f_{6}(x+z)=0$, which is mixed of a quadratic and an additive functional equations. Also, we obtain its general solution from the stability results.

Copyright $@ 2008$ Kil-Woung Jun et al. This is an open access article distributed under the Creative Commons Attribution License, which permits unrestricted use, distribution, and reproduction in any medium, provided the original work is properly cited.

\section{Introduction}

In 1940, Ulam [1] raised the following question. Under what conditions does there exist an additive mapping near an approximately additive mapping?

In 1941, Hyers [2] proved that if $f: V \rightarrow X$ is a mapping satisfying

$$
\|f(x+y)-f(x)-f(y)\| \leq \delta
$$

for all $x, y \in V$, where $V$ and $X$ are Banach spaces and $\delta$ is a given positive number, then there exists a unique additive mapping $T: V \rightarrow X$ such that

$$
\|f(x)-T(x)\| \leq \delta
$$

for all $x \in V$. In 1978, Rassias [3] gave a significant generalization of Hyers' result. Rassias [4] during the 27th International Symposium on Functional Equations, that took place in BielskoBiala, Poland, in 1990, asked the question whether such a theorem can also be proved for a more general setting. Gadja [5] following Rassias's approach [3] gave an affirmative solution to the question. Recently, Găvruţa [6] obtained a further generalization of Rassias' theorem, 
the so-called generalized Hyers-Ulam-Rassias stability (see also [4, 7-10]). Jun et al. [11-13] also obtained the Hyers-Ulam-Rassias stability of the Pexider equation of $f(x+y)=g(x)+$ $h(y)$. Quadratic functional equation was used to characterize inner product spaces [14]. Several other functional equations were also to characterize inner product spaces. A square norm on an inner product space satisfies the important parallelogram equality

$$
\|x+y\|^{2}+\|x-y\|^{2}=2\left(\|x\|^{2}+\|y\|^{2}\right) .
$$

The functional equation

$$
f(x+y)+f(x-y)=2 f(x)+2 f(y)
$$

is related to a symmetric biadditive function [14]. It is natural that each equation is called a quadratic functional equation. A stability problem for the quadratic functional equation was proved by Skof [15] for a function $f: V \rightarrow X$, where $V$ is a normed space and $X$ a Banach space. Cholewa [16] noticed that the theorem of Skof is still true if the relevant domain $V$ is replaced by an Abelian group. Czerwik [17] proved the Hyers-Ulam-Rassias stability of the quadratic functional equation. Jun and Lee [13, 18-22] proved the Hyers-Ulam-Rassias stability of the Pexiderized quadratic equation

$$
f(x+y)+g(x-y)=2 h(x)+2 k(y) .
$$

Now, we introduce the following new Pexider type functional equation:

$$
f_{1}(x+y+z)+f_{2}(x-y)+f_{3}(z-x)-f_{4}(x-y-z)-f_{5}(x+y)-f_{6}(x+z)=0,
$$

which is mixed of a quadratic and an additive functional equations. In this paper, we establish the generalized Hyers-Ulam-Rassias stability for (1.6) on the punctured domain $V \backslash\{0\}$ and obtain its general solution from the stability results. Throughout this paper, let $V$ and $X$ be a normed space and a Banach space, respectively. For convenience, we employ the operators as follows: for a given function $\varphi: V \backslash\{0\} \times V \backslash\{0\} \times V \backslash\{0\} \rightarrow[0, \infty)$, let $\varphi^{\prime}, \varphi_{e}, \varphi_{e}^{\prime}:(V \backslash\{0\})^{3} \rightarrow[0, \infty)$, $M, M^{\prime}, M_{e}, M_{e}^{\prime}: V \backslash\{0\} \rightarrow[0, \infty)$ be functions defined by

$$
\begin{aligned}
& \varphi^{\prime}(x, y, z):=\frac{1}{2}[\varphi(x, y, z)+\varphi(-x, y, z)] \\
& \varphi_{e}(x, y, z):=\frac{1}{2}[\varphi(x, y, z)+\varphi(-x,-y,-z)] \\
& \varphi_{e}^{\prime}(x, y, z):=\frac{1}{4}[\varphi(x, y, z)+\varphi(-x, y, z)+\varphi(-x,-y,-z)+\varphi(x,-y,-z)] \\
& M(x):=\varphi^{\prime}\left(\frac{x}{2}, \frac{3 x}{2},-\frac{x}{2}\right)+2 \varphi^{\prime}\left(\frac{x}{2}, \frac{x}{2},-\frac{x}{2}\right)+\varphi^{\prime}\left(\frac{x}{2}, \frac{x}{2}, \frac{x}{2}\right) \\
& M^{\prime}(x):=\varphi^{\prime}\left(\frac{x}{2}, \frac{x}{2},-\frac{3 x}{2}\right)+2 \varphi^{\prime}\left(\frac{x}{2}, \frac{x}{2},-\frac{x}{2}\right)+\varphi^{\prime}\left(\frac{x}{2}, \frac{x}{2}, \frac{x}{2}\right) \\
& M^{\prime}(x):=\varphi^{\prime}\left(\frac{x}{2}, \frac{3 x}{2},-\frac{x}{2}\right)+2 \varphi^{\prime}\left(\frac{x}{2}, \frac{x}{2},-\frac{x}{2}\right)+\varphi^{\prime}\left(\frac{x}{2}, \frac{x}{2}, \frac{x}{2}\right) \\
& M_{e}^{\prime}(x):=\varphi_{e}^{\prime}\left(\frac{x}{2}, \frac{x}{2},-\frac{3 x}{2}\right)+2 \varphi_{e}^{\prime}\left(\frac{x}{2}, \frac{x}{2},-\frac{x}{2}\right)+\varphi_{e}^{\prime}\left(\frac{x}{2}, \frac{x}{2}, \frac{x}{2}\right)
\end{aligned}
$$

for all $x, y, z \in V \backslash\{0\}$. 


\section{Generalized Hyers-Ulam-Rassias stability}

We need the following lemma to prove our main results.

Lemma 2.1. Let a be a positive real number. Let $\Phi: V \backslash\{0\} \rightarrow[0, \infty)$ be a map such that

$$
\widetilde{\Phi}(x):=\sum_{l=0}^{\infty} \frac{1}{a^{l+1}} \Phi\left(2^{l} x\right)<\infty \quad \forall x \in V \backslash\{0\}
$$

or

$$
\widetilde{\Phi}(x):=\sum_{l=0}^{\infty} a^{l} \Phi\left(\frac{x}{2^{l+1}}\right)<\infty \quad \forall x \in V \backslash\{0\} .
$$

Suppose that the function $f: V \rightarrow X$ satisfies the inequality

$$
\left\|f(x)-\frac{f(2 x)}{a}\right\| \leq \frac{\Phi(x)}{a}
$$

for all $x \in V \backslash\{0\}$ and $f(0)=0$. Then, there exists exactly one function $F: V \rightarrow X$ satisfying

$$
\|f(x)-F(x)\| \leq \widetilde{\Phi}(x) \quad \forall x \in V \backslash\{0\}, \quad a F(x)=F(2 x) \quad \forall x \in V .
$$

Proof. First we assume that $\Phi$ satisfies

$$
\sum_{l=0}^{\infty} \frac{\Phi\left(2^{l} x\right)}{a^{l+1}}<\infty
$$

for all $x \in V \backslash\{0\}$. Replacing $x$ by $2^{n} x$ and dividing it by $a^{n}$ in (2.3), we have

$$
\left\|\frac{f\left(2^{n} x\right)}{a^{n}}-\frac{f\left(2^{n+1} x\right)}{a^{n+1}}\right\| \leq \frac{\Phi\left(2^{n} x\right)}{a^{n+1}}
$$

for all $n \in \mathbb{N}$ and $x \in V \backslash\{0\}$. Induction argument implies that

$$
\left\|f(x)-\frac{f\left(2^{n} x\right)}{a^{n}}\right\| \leq \sum_{s=0}^{n-1} \frac{\Phi\left(2^{s} x\right)}{a^{s+1}}
$$

for all $n \in \mathbb{N}$ and $x \in V \backslash\{0\}$. Hence

$$
\left\|\frac{f\left(2^{n} x\right)}{a^{n}}-\frac{f\left(2^{m} x\right)}{a^{m}}\right\| \leq \sum_{s=n}^{m-1} \frac{\Phi\left(2^{s} x\right)}{a^{s+1}}
$$

for all positive integers $m>n$ and $x \in V \backslash\{0\}$. This shows that $\left\{f\left(2^{n} x\right) / a^{n}\right\}$ is a Cauchy sequence for $x \in V \backslash\{0\}$ and thus converges. Therefore, we can define $F: V \rightarrow X$ such that

$$
F(x)= \begin{cases}\lim _{n \rightarrow \infty} \frac{f\left(2^{n} x\right)}{a^{n}}, & \text { if } x \neq 0 \\ 0, & \text { if } x=0\end{cases}
$$


for all $x \in V$. From (2.7) and the definition of $F$, we obtain

$$
\|f(x)-F(x)\| \leq \tilde{\Phi}(x), \quad a F(x)=F(2 x)
$$

for all $x \in V \backslash\{0\}$. Now, let $F^{\prime}: V \backslash\{0\} \rightarrow X$ be another mapping satisfying the above inequality and equality. Then, it follows that

$$
\begin{aligned}
\left\|F(x)-F^{\prime}(x)\right\| & \leq\left\|\frac{f\left(2^{m} x\right)}{a^{m}}-\frac{F\left(2^{m} x\right)}{a^{m}}\right\|+\left\|\frac{f\left(2^{m} x\right)}{a^{m}}-\frac{F^{\prime}\left(2^{m} x\right)}{a^{m}}\right\| \\
& \leq \frac{\widetilde{\Phi}\left(2^{m} x\right)}{a^{m}}
\end{aligned}
$$

which tends to zero by the definition of $\widetilde{\Phi}$ as $m \rightarrow \infty$ for all $x \in V$. So we can conclude that $F(x)=F^{\prime}(x)$ for all $x \in V$. This proves the uniqueness of $F$.

Next we assume that $\Phi$ satisfies

$$
\sum_{l=0}^{\infty} a^{l} \Phi\left(\frac{x}{2^{l+1}}\right)<\infty
$$

for all $x \in V \backslash\{0\}$. Replacing $x$ by $2^{-n-1} x$ and multiplying it by $a^{n+1}$ in (2.3), we have

$$
\left\|a^{n} f\left(2^{-n} x\right)-a^{n+1} f\left(2^{-n-1} x\right)\right\| \leq a^{n} \Phi\left(2^{-n-1} x\right)
$$

for all $n \in \mathbb{N}$ and $x \in V \backslash\{0\}$. Induction argument implies that

$$
\left\|f(x)-a^{n} f\left(2^{-n} x\right)\right\| \leq \sum_{s=0}^{n-1} a^{s} \Phi\left(2^{-s-1} x\right)
$$

for all $n \in \mathbb{N}$ and $x \in V \backslash\{0\}$. Hence

$$
\left\|a^{n} f\left(2^{-n} x\right)-a^{m} f\left(2^{-m} x\right)\right\| \leq \sum_{s=n}^{m-1} a^{s} \Phi\left(2^{-s-1} x\right)
$$

for all positive integers $m>n$ and $x \in V \backslash\{0\}$. This shows that $\left\{a^{n} f\left(2^{-n} x\right)\right\}$ is a Cauchy sequence for $x \in V \backslash\{0\}$ and thus converges. Therefore we can define $F: V \rightarrow X$ such that

$$
F(x)= \begin{cases}\lim _{n \rightarrow \infty} a^{n} f\left(2^{-n} x\right) & \text { if } x \neq 0 \\ 0 & \text { if } x=0\end{cases}
$$

for all $x \in V$. From (2.14) and the definition of $F$, we obtain

$$
\|f(x)-F(x)\| \leq \widetilde{\Phi}(x), \quad a F(x)=F(2 x)
$$

for all $x \in V \backslash\{0\}$.

The uniqueness of $F$ is proved similarly as the first case. This completes the proof.

We establish the stability results for the even functions in Theorems 2.2 and 2.3. 
Theorem 2.2. Let $\varphi: V \backslash\{0\} \times V \backslash\{0\} \times V \backslash\{0\} \rightarrow[0, \infty)$ be a function such that

$$
\tilde{\varphi}(x, y, z):=\sum_{l=0}^{\infty} \frac{1}{4^{l+1}} \varphi\left(2^{l} x, 2^{l} y, 2^{l} z\right)<\infty
$$

holds for all $x, y, z \in V \backslash\{0\}$. If the even functions $f_{1}, f_{2}, f_{3}, f_{4}, f_{5}, f_{6}: V \rightarrow X$ satisfy the inequality

$$
\left\|f_{1}(x+y+z)+f_{2}(x-y)+f_{3}(x-z)-f_{4}(x-y-z)-f_{5}(x+y)-f_{6}(x+z)\right\| \leq \varphi(x, y, z)
$$

for all $x, y, z \in V \backslash\{0\}$, then there exists exactly one quadratic function $Q: V \rightarrow X$ satisfying the inequalities

$$
\begin{aligned}
\left\|f_{1}(x)-f_{1}(0)-Q(x)\right\| \leq & \frac{1}{2}\left[\varphi^{\prime}\left(\frac{x}{2}, \frac{3}{2} x,-x\right)+\varphi^{\prime}\left(\frac{x}{2}, \frac{x}{2},-x\right)\right] \\
& +\frac{1}{2} \widetilde{M}(2 x)+\widetilde{M}(x)+\varphi^{\prime}\left(\frac{x}{4}, \frac{x}{4},-\frac{x}{2}\right)+\varphi^{\prime}\left(\frac{x}{4}, \frac{x}{4}, \frac{x}{2}\right), \\
\left\|f_{2}(x)-f_{2}(0)-Q(x)\right\| \leq & \widetilde{M}(x)+\varphi^{\prime}\left(\frac{x}{4}, \frac{3 x}{4},-\frac{x}{4}\right)+\varphi^{\prime}\left(\frac{x}{4}, \frac{x}{4}, \frac{x}{4}\right), \\
\left\|f_{3}(x)-f_{3}(0)-Q(x)\right\| \leq & \widetilde{M}^{\prime}(x)+\varphi^{\prime}\left(\frac{x}{4}, \frac{x}{4},-\frac{3 x}{4}\right)+\varphi^{\prime}\left(\frac{x}{4}, \frac{x}{4}, \frac{x}{4}\right), \\
\left\|f_{4}(x)-f_{4}(0)-Q(x)\right\| \leq & \frac{1}{2}\left[\varphi^{\prime}\left(\frac{x}{2}, \frac{3}{2} x,-x\right)+\varphi^{\prime}\left(\frac{x}{2}, \frac{x}{2},-x\right)\right] \\
& +\frac{1}{2} \widetilde{M}(2 x)+\widetilde{M}(x)+\varphi^{\prime}\left(\frac{x}{4}, \frac{x}{4},-\frac{x}{2}\right)+\varphi^{\prime}\left(\frac{x}{4}, \frac{x}{4}, \frac{x}{2}\right), \\
\left\|f_{5}(x)-f_{5}(0)-Q(x)\right\| \leq & \widetilde{M}(x)+\varphi^{\prime}\left(\frac{x}{4}, \frac{3 x}{4},-\frac{x}{4}\right)+\varphi^{\prime}\left(\frac{x}{4}, \frac{x}{4}, \frac{x}{4}\right), \\
\left\|f_{6}(x)-f_{6}(0)-Q(x)\right\| \leq & \widetilde{M}(x)+\varphi^{\prime}\left(\frac{x}{4}, \frac{x}{4},-\frac{3 x}{4}\right)+\varphi^{\prime}\left(\frac{x}{4}, \frac{x}{4}, \frac{x}{4}\right)
\end{aligned}
$$

for all $x \in V \backslash\{0\}$, where

$$
\widetilde{M}(x):=\sum_{l=0}^{\infty} \frac{1}{4^{l+1}} M\left(2^{l} x\right), \quad \widetilde{M}^{\prime}(x):=\sum_{l=0}^{\infty} \frac{1}{4^{l+1}} M^{\prime}\left(2^{l} x\right)
$$

for all $x \in V \backslash\{0\}$. Moreover, the function $Q$ is given by

$$
Q(x)=\lim _{n \rightarrow \infty} \frac{f_{k}\left(2^{n} x\right)}{4^{n}}
$$

for all $x \in V$ and for $k=1,2,3,4,5,6$. 
Proof. Replace $x$ by $-x$ in (2.18) to obtain

$$
\left\|f_{1}(x-y-z)+f_{2}(x+y)+f_{3}(x+z)-f_{4}(x+y+z)-f_{5}(x-y)-f_{6}(x-z)\right\| \leq \varphi(-x, y, z)
$$

for all $x, y, z \in V \backslash\{0\}$. From (2.18) and (2.23), we get

$$
\begin{aligned}
& \|\left(f_{1}+f_{4}\right)(x+y+z)+\left(f_{2}+f_{5}\right)(x-y)+\left(f_{3}+f_{6}\right)(x-z) \\
& \quad-\left(f_{1}+f_{4}\right)(x-y-z)-\left(f_{2}+f_{5}\right)(x+y)-\left(f_{3}+f_{6}\right)(x+z) \| \leq \varphi(-x, y, z)+\varphi(x, y, z)
\end{aligned}
$$

for all $x, y, z \in V \backslash\{0\}$. Let the functions $F, G, H: V \rightarrow X$ be defined by

$$
\begin{aligned}
F(x) & =\frac{1}{2}\left[f_{1}(x)+f_{4}(x)-f_{1}(0)-f_{4}(0)\right] \\
G(x) & =\frac{1}{2}\left[f_{2}(x)+f_{5}(x)-f_{2}(0)-f_{5}(0)\right] \\
H(x) & =\frac{1}{2}\left[f_{3}(x)+f_{6}(x)-f_{3}(0)-f_{6}(0)\right]
\end{aligned}
$$

for all $x, y, z \in V$. Then, it follows from (2.24) that

$$
\|F(x+y+z)+G(x-y)+H(x-z)-F(x-y-z)-G(x+y)-H(x+z)\| \leq \varphi^{\prime}(x, y, z)
$$

for all $x, y, z \in V \backslash\{0\}$, where $\varphi^{\prime}(x, y, z)=(1 / 2)[\varphi(x, y, z)+\varphi(-x, y, z)]$. Replace $y$ and $z$ by $x$ and $-x$ in (2.26) to get

$$
\|H(2 x)-G(2 x)\| \leq \varphi^{\prime}(x, x,-x)
$$

for all $x \in V \backslash\{0\}$.

Replacing $y, z$ by $x$ in (2.26) and using (2.27), we get

$$
\|F(3 x)-F(x)-2 G(2 x)\| \leq \varphi^{\prime}(x, x, x)+\varphi^{\prime}(x, x,-x)
$$

for all $x \in V \backslash\{0\}$. Replacing $x, y, z$ by $x, 3 x,-x$ in (2.26) and using (2.27), one obtains

$$
\|F(3 x)-F(x)-G(4 x)+2 G(2 x)\| \leq \varphi^{\prime}(x, 3 x,-x)+\varphi^{\prime}(x, x,-x)
$$

for all $x \in V \backslash\{0\}$. From (2.28) and the above inequality, we have

$$
\|G(4 x)-4 G(2 x)\| \leq \varphi^{\prime}(x, 3 x,-x)+2 \varphi^{\prime}(x, x,-x)+\varphi^{\prime}(x, x, x)
$$

for all $x \in V \backslash\{0\}$. Replacing $x$ by $x / 2$ and dividing it by 4 in the above inequality, we get

$$
\left\|G(x)-\frac{G(2 x)}{4}\right\| \leq \frac{M(x)}{4}
$$


Kil-Woung Jun et al.

for all $x \in V \backslash\{0\}$. By Lemma 2.1, there exists $\lim _{n \rightarrow \infty}\left(G\left(2^{n} x\right) / 4^{n}\right)$ for all $x \in V$ satisfying

$$
\left\|G(x)-\lim _{n \rightarrow \infty} \frac{G\left(2^{n} x\right)}{4^{n}}\right\| \leq \widetilde{M}(x)
$$

for all $x \in V \backslash\{0\}$, where

$$
\widetilde{M}(x):=\sum_{l=0}^{\infty} \frac{1}{4^{l+1}} M\left(2^{l} x\right) .
$$

By the similar method in obtaining inequality (2.32), we get

$$
\left\|H(x)-\lim _{n \rightarrow \infty} \frac{H\left(2^{n} x\right)}{4^{n}}\right\| \leq \widetilde{M}^{\prime}(x)
$$

for all $x \in V \backslash\{0\}$, where

$$
\widetilde{M}^{\prime}(x):=\sum_{l=0}^{\infty} \frac{1}{4^{l+1}} M^{\prime}\left(2^{l} x\right) .
$$

From (2.27), we have

$$
\lim _{n \rightarrow \infty} \frac{G\left(2^{n} x\right)}{4^{n}}=\lim _{n \rightarrow \infty} \frac{H\left(2^{n} x\right)}{4^{n}}
$$

for all $x \in V$. From (2.36), we can define a map $Q: V \rightarrow X$ by

$$
Q(x)=\lim _{n \rightarrow \infty} \frac{G\left(2^{n} x\right)}{4^{n}}
$$

for all $x \in V$. It follows from (2.26), (2.32), and (2.37) that

$$
\begin{aligned}
\|F(x)-Q(x)\| \leq & \frac{1}{2}\left\|F(x)+G(x)+H\left(\frac{3}{2} x\right)-G(2 x)-H\left(\frac{x}{2}\right)\right\|+\frac{1}{2}\|G(x)-Q(x)\| \\
& +\left\|F(x)+G(x)+H\left(\frac{1}{2} x\right)-H\left(\frac{3}{2} x\right)\right\|+\frac{1}{2}\|G(2 x)-Q(2 x)\| \\
\leq & \frac{1}{2} \varphi^{\prime}\left(\frac{x}{2}, \frac{3}{2} x,-x\right)+\frac{1}{2} \widetilde{M}(2 x)+\frac{1}{2} \varphi^{\prime}\left(\frac{x}{2}, \frac{x}{2},-x\right)+\widetilde{M}(x)
\end{aligned}
$$

for all $x \in V \backslash\{0\}$. Replacing $x$ by $2^{n} x$, dividing it by $4^{n}$ in the above inequality and taking the limit in the resulted inequality as $n \rightarrow \infty$, we have

$$
\lim _{n \rightarrow \infty} \frac{F\left(2^{n} x\right)}{4^{n}}=Q(x)
$$

for all $x \in V$. Using (2.26), (2.36), (2.37), and (2.39), we obtain

$$
Q(x+y+z)+Q(x-y)+Q(z-x)-Q(x-y-z)-Q(x+y)-Q(x+z)=0
$$


for all $x, y, z \in V \backslash\{0\}$. Replacing $x$ and $z$ by $x / 2$ in $(2.40)$ and using the fact $Q(0)=0$, we have

$$
Q(x+y)+Q\left(\frac{x}{2}-y\right)-Q(-y)-Q\left(\frac{x}{2}+y\right)-Q(x)=0
$$

for all $x, y \in V$. Replace $x$ and $z$ by $x / 2$ and $-x / 2$ in (2.40) to have

$$
Q(y)+Q\left(\frac{x}{2}-y\right)+Q(x)-Q(x-y)-Q\left(\frac{x}{2}+y\right)=0
$$

for all $x, y \in V$. Subtracting (2.41) from (2.42) and using the evenness of $Q$, we lead to

$$
Q(x+y)+Q(x-y)-2 Q(x)-2 Q(y)=0,
$$

for all $x, y \in V$.

On the other hand, it follows from (2.18) and (2.23) that

$$
\begin{aligned}
& \|\left(f_{1}-f_{4}\right)(x+y+z)+\left(f_{2}-f_{5}\right)(x-y)+\left(f_{3}-f_{6}\right)(x-z) \\
& \quad+\left(f_{1}-f_{4}\right)(x-y-z)+\left(f_{2}-f_{5}\right)(x+y)+\left(f_{3}-f_{6}\right)(-x+z) \| \leq \varphi(-x, y, z)+\varphi(x, y, z)
\end{aligned}
$$

for all $x, y, z \in V \backslash\{0\}$. Let the functions $F^{\prime}, G^{\prime}, H^{\prime}: V \rightarrow X$ be defined by

$$
F^{\prime}(x)=\frac{1}{2}\left[f_{1}(x)-f_{4}(x)\right], \quad G^{\prime}(x)=\frac{1}{2}\left[f_{2}(x)-f_{5}(x)\right], \quad H^{\prime}(x)=\frac{1}{2}\left[f_{3}(x)-f_{6}(x)\right]
$$

for all $x, y, z \in V$.

From (2.44), we have

$$
\left\|F^{\prime}(x+y+z)+G^{\prime}(x-y)+H^{\prime}(x-z)+F^{\prime}(x-y-z)+G^{\prime}(x+y)+H^{\prime}(x+z)\right\| \leq \varphi^{\prime}(x, y, z)
$$

for all $x, y, z \in V \backslash\{0\}$. Replace $y, z$ by $x$ in (2.46) to get

$$
\left\|F^{\prime}(3 x)+F^{\prime}(x)+G^{\prime}(2 x)+G^{\prime}(0)+H^{\prime}(2 x)+H^{\prime}(0)\right\| \leq \varphi^{\prime}(x, x, x)
$$

for all $x, y, z \in V \backslash\{0\}$. Replace $x, y, z$ by $x, 3 x,-x$ in (2.46) to get

$$
\left\|F^{\prime}(3 x)+F^{\prime}(x)+G^{\prime}(2 x)+G^{\prime}(4 x)+H^{\prime}(2 x)+H^{\prime}(0)\right\| \leq \varphi^{\prime}(x, 3 x,-x)
$$

for all $x, y, z \in V \backslash\{0\}$. From (2.47) and the above inequality, we have

$$
\left\|G^{\prime}(4 x)-G^{\prime}(0)\right\| \leq \varphi^{\prime}(x, 3 x,-x)+\varphi^{\prime}(x, x, x)
$$

for all $x \in V \backslash\{0\}$.

Replace $x, y, z$ by $x, x,-3 x$ in (2.46) to get

$$
\left\|F^{\prime}(3 x)+F^{\prime}(x)+G^{\prime}(2 x)+G^{\prime}(0)+H^{\prime}(2 x)+H^{\prime}(4 x)\right\| \leq \varphi^{\prime}(x, x,-3 x)
$$


for all $x, y, z \in V \backslash\{0\}$. From (2.47) and the above inequality, we get

$$
\left\|H^{\prime}(4 x)-H^{\prime}(0)\right\| \leq \varphi^{\prime}(x, x,-3 x)+\varphi^{\prime}(x, x, x)
$$

for all $x \in V \backslash\{0\}$. It follows from (2.46) that

$$
\begin{aligned}
\left\|F^{\prime}(4 x)-F^{\prime}(0)\right\| \leq & \left\|F^{\prime}(0)+G^{\prime}(0)+H^{\prime}(3 x)+F^{\prime}(2 x)+G^{\prime}(2 x)+H^{\prime}(x)\right\| \\
& +\left\|F^{\prime}(4 x)+G^{\prime}(0)+H^{\prime}(x)+F^{\prime}(2 x)+G^{\prime}(2 x)+H^{\prime}(3 x)\right\| \\
\leq & \varphi^{\prime}(x, x,-2 x)+\varphi^{\prime}(x, x, 2 x)
\end{aligned}
$$

for all $x \in V \backslash\{0\}$. By the definitions of $F, G, H, F^{\prime}, G^{\prime}, H^{\prime}$, we have

$$
\begin{aligned}
& f_{1}(x)-f_{1}(0)-Q(x)=F(x)+F^{\prime}(x)-F^{\prime}(0)-Q(x), \\
& f_{2}(x)-f_{2}(0)-Q(x)=G(x)+G^{\prime}(x)-F^{\prime}(0)-Q(x), \\
& f_{3}(x)-f_{3}(0)-Q(x)=H(x)+H^{\prime}(x)-H^{\prime}(0)-Q(x), \\
& f_{4}(x)-f_{4}(0)-Q(x)=F(x)-F^{\prime}(x)+F^{\prime}(0)-Q(x), \\
& f_{5}(x)-f_{5}(0)-Q(x)=G(x)-G^{\prime}(x)+G^{\prime}(0)-Q(x), \\
& f_{6}(x)-f_{6}(0)-Q(x)=H(x)-H^{\prime}(x)+H^{\prime}(0)-Q(x)
\end{aligned}
$$

for all $x \in V \backslash\{0\}$. Hence by using (2.32), (2.34), (2.36), (2.37), (2.38), (2.49), (2.51), and (2.52), the inequalities in (2.19) can be shown. The uniqueness of $Q$ follows from Lemma 2.1.

Theorem 2.3. Let $\varphi: V \backslash\{0\} \times V \backslash\{0\} \times V \backslash\{0\} \rightarrow[0, \infty)$ be a function such that

$$
\tilde{\varphi}(x, y, z):=\sum_{l=0}^{\infty} 4^{l} \varphi\left(\frac{x}{2^{l+1}}, \frac{y}{2^{l+1}}, \frac{z}{2^{l+1}}\right)<\infty
$$

holds for all $x, y, z \in V \backslash\{0\}$. If the even functions $f_{1}, f_{2}, f_{3}, f_{4}, f_{5}, f_{6}: V \rightarrow X$ satisfy inequality (2.18) for all $x, y, z \in V \backslash\{0\}$, then there exists exactly one quadratic function $Q: V \rightarrow X$ satisfying inequalities (2.19) for all $x \in V \backslash\{0\}$, where

$$
\widetilde{M}(x):=\sum_{l=0}^{\infty} 4^{l} M\left(\frac{x}{2^{l+1}}\right), \quad \widetilde{M}^{\prime}(x):=\sum_{l=0}^{\infty} 4^{l} M^{\prime}\left(\frac{x}{2^{l+1}}\right) .
$$

Moreover, the function $Q$ is given by

$$
Q(x)=\lim _{n \rightarrow \infty} 4^{n}\left(f_{k}\left(2^{-n} x\right)-f_{k}(0)\right)
$$

for all $x \in V$ and for $k=1,2,3,4,5,6$.

Proof. The proof is similar to that of Theorem 2.2.

Applying Theorems 2.2 and 2.3, we get the following corollary in the sense of Rassias inequality.

Corollary 2.4. Let $p \neq 2$ and $\varepsilon>0$. If the even functions $f_{i}: V \rightarrow X, i=1,2, \ldots, 6$, satisfy

$$
\begin{aligned}
& \left\|f_{1}(x+y+z)+f_{2}(x-y)+f_{3}(x-z)-f_{4}(x-y-z)-f_{5}(x+y)-f_{6}(x+z)\right\| \\
& \quad \leq \varepsilon\left(\|x\|^{p}+\|y\|^{p}+\|z\|^{p}\right)
\end{aligned}
$$

for all $x, y, z \in V \backslash\{0\}$. 
Then there exist exactly one quadratic function $Q: V \rightarrow X$ satisfying

$$
\begin{aligned}
& \left\|f_{1}(x)-f_{1}(0)-Q(x)\right\| \leq\left[1+\frac{\left(3^{p}+11\right)\left(2^{p}+2\right)}{2 \cdot 2^{p}\left|2^{p}-4\right|}+\frac{7+3^{p}}{2 \cdot 2^{p}}+\frac{4}{4^{p}}\right] \cdot \varepsilon \cdot\|x\|^{p}, \\
& \left\|f_{4}(x)-f_{4}(0)-Q(x)\right\| \leq\left[1+\frac{\left(3^{p}+11\right)\left(2^{p}+2\right)}{2 \cdot 2^{p}\left|2^{p}-4\right|}+\frac{7+3^{p}}{2 \cdot 2^{p}}+\frac{4}{4^{p}}\right] \cdot \varepsilon \cdot\|x\|^{p}, \\
& \left\|f_{j}(x)-f_{j}(0)-Q(x)\right\| \leq\left[\frac{3^{p}+11}{2^{p}\left|2^{p}-4\right|}+\frac{3^{p}+5}{4^{p}}\right] \cdot \varepsilon \cdot\|x\|^{p}
\end{aligned}
$$

for all $x \in V \backslash\{0\}$ and $j=2,3,5,6$. Moreover, the function $Q$ is given by

$$
Q(x)= \begin{cases}\lim _{n \rightarrow \infty} \frac{f_{k}\left(2^{n} x\right)}{4^{n}} & \text { if } p<2, \\ \lim _{n \rightarrow \infty} 4^{n}\left(f_{k}\left(2^{-n} x\right)-f_{k}(0)\right) & \text { if } p>2\end{cases}
$$

for all $x \in V \backslash\{0\}$ and $k=1,2,3,4,5,6$

Proof. Apply Theorem 2.2 for $p<2$ and Theorem 2.3 for $p>2$.

We establish Theorems 2.5 and 2.6 for the odd functions.

Theorem 2.5. Let $\varphi: V \backslash\{0\} \times V \backslash\{0\} \times V \backslash\{0\} \rightarrow[0, \infty)$ be a function such that

$$
\widehat{\varphi}(x, y, z):=\sum_{l=0}^{\infty} \frac{1}{2^{l+1}} \varphi\left(2^{l} x, 2^{l} y, 2^{l} z\right)<\infty
$$

holds for all $x, y, z \in V \backslash\{0\}$. If the odd functions $f_{1}, f_{2}, f_{3}, f_{4}, f_{5}, f_{6}: V \rightarrow X$ satisfy

$$
\left\|f_{1}(x+y+z)+f_{2}(x-y)+f_{3}(x-z)-f_{4}(x-y-z)-f_{5}(x+y)-f_{6}(x+z)\right\| \leq \varphi(x, y, z)
$$

for all $x, y, z \in V \backslash\{0\}$, then there exist exactly three additive functions $A, A_{1}, A_{2}: V \rightarrow X$ satisfying

$$
\begin{aligned}
&\left\|f_{1}(x)-A(x)+A_{1}(x)+A_{2}(x)\right\| \leq \varphi^{\prime}\left(\frac{x}{4}, \frac{x}{4},-\frac{x}{2}\right)+\varphi^{\prime}\left(\frac{x}{4}, \frac{x}{4}, \frac{x}{2}\right) \\
&+2 \widehat{M}\left(\frac{x}{2}\right)+\widehat{\varphi}^{\prime}\left(\frac{x}{2}, \frac{x}{2}, x\right)+\widehat{\varphi}^{\prime}\left(\frac{x}{2},-\frac{x}{2}, x\right), \\
&\left\|f_{2}(x)-A(x)-A_{1}(x)\right\| \leq \widehat{M}(x)+\widehat{\varphi}^{\prime}\left(\frac{x}{2}, \frac{3 x}{2},-\frac{x}{2}\right)+\widehat{\varphi}^{\prime}\left(\frac{x}{2}, \frac{x}{2}, \frac{x}{2}\right), \\
&\left\|f_{3}(x)-A(x)-A_{2}(x)\right\| \leq \widehat{M}^{\prime}(x)+\widehat{\varphi}^{\prime}\left(\frac{x}{2},-\frac{x}{2}, \frac{3 x}{2}\right)+\widehat{\varphi}^{\prime}\left(\frac{x}{2}, \frac{x}{2}, \frac{x}{2}\right), \\
&\left\|f_{4}(x)-A(x)-A_{1}(x)-A_{2}(x)\right\| \leq \varphi^{\prime}\left(\frac{x}{4}, \frac{x}{4},-\frac{x}{2}\right)+\varphi^{\prime}\left(\frac{x}{4}, \frac{x}{4}, \frac{x}{2}\right) \\
&+2 \widehat{M}\left(\frac{x}{2}\right)+\widehat{\varphi}^{\prime}\left(\frac{x}{2}, \frac{x}{2}, x\right)+\widehat{\varphi}^{\prime}\left(\frac{x}{2},-\frac{x}{2}, x\right), \\
&\left\|f_{5}(x)-A(x)+A_{1}(x)\right\| \leq \widehat{M}^{\prime}(x)+\widehat{\varphi}^{\prime}\left(\frac{x}{2}, \frac{3 x}{2},-\frac{x}{2}\right)+\widehat{\varphi}^{\prime}\left(\frac{x}{2}, \frac{x}{2}, \frac{x}{2}\right), \\
&\left\|f_{6}(x)-A(x)+A_{2}(x)\right\| \leq \widehat{M}^{\prime}(x)+\widehat{\varphi}^{\prime}\left(\frac{x}{2},-\frac{x}{2}, \frac{3 x}{2}\right)+\widehat{\varphi}^{\prime}\left(\frac{x}{2}, \frac{x}{2}, \frac{x}{2}\right)
\end{aligned}
$$


Kil-Woung Jun et al.

for all $x \in V \backslash\{0\}$, where

$$
\begin{gathered}
\widehat{M}(x):=\sum_{l=0}^{\infty} \frac{1}{2^{l+1}} M\left(2^{l} x\right), \quad \widehat{M}^{\prime}(x):=\sum_{l=0}^{\infty} \frac{1}{2^{l+1}} M^{\prime}\left(2^{l} x\right), \\
\widehat{\varphi}^{\prime}(x, y, z):=\sum_{l=0}^{\infty} \frac{1}{2^{l+1}} \varphi^{\prime}\left(2^{l} x, 2^{l} y, 2^{l} z\right) .
\end{gathered}
$$

Moreover, the functions $A, A_{1}, A_{2}$ are given by

$$
\begin{aligned}
& A(x)=\lim _{n \rightarrow \infty} \frac{f_{1}\left(2^{n} x\right)+f_{4}\left(2^{n} x\right)}{2^{n+1}}, \\
& A_{1}(x)=\lim _{n \rightarrow \infty} \frac{f_{2}\left(2^{n} x\right)-f_{5}\left(2^{n} x\right)}{2^{n+1}}, \\
& A_{2}(x)=\lim _{n \rightarrow \infty} \frac{f_{3}\left(2^{n} x\right)-f_{6}\left(2^{n} x\right)}{2^{n+1}}
\end{aligned}
$$

for all $x \in V$.

Proof. Replace $x$ by $-x$ in (2.59) to obtain

$$
\left\|-f_{1}(x-y-z)-f_{2}(x+y)-f_{3}(x+z)+f_{4}(x+y+z)+f_{5}(x-y)+f_{6}(x-z)\right\| \leq \varphi(-x, y, z)
$$

for all $x, y, z \in V \backslash\{0\}$. Let the functions $F, G, H: V \rightarrow X$ be defined by

$$
F(x)=\frac{1}{2}\left[f_{1}(x)+f_{4}(x)\right], \quad G(x)=\frac{1}{2}\left[f_{2}(x)+f_{5}(x)\right], \quad H(x)=\frac{1}{2}\left[f_{3}(x)+f_{6}(x)\right]
$$

for all $x, y, z \in V$. From (2.59) and (2.64), we get

$$
\|F(x+y+z)+G(x-y)+H(x-z)-F(x-y-z)-G(x+y)-H(x+z)\| \leq \varphi^{\prime}(x, y, z)
$$

for all $x, y, z \in V \backslash\{0\}$. From (2.66), we have

$$
\|H(2 x)-G(2 x)\| \leq \varphi^{\prime}(x, x,-x),
$$

for all $x \in V \backslash\{0\}$. It follows from (2.66) and (2.67) that

$$
\begin{aligned}
\|G(4 x)-2 G(2 x)\|= & \|-F(3 x)-F(x)+G(2 x)+G(4 x)-H(2 x)\| \\
& +\|2 H(2 x)-2 G(2 x)\|+\|F(3 x)+F(x)-G(2 x)-H(2 x)\| \\
\leq & \varphi^{\prime}(x, x, x)+2 \varphi^{\prime}(x, x,-x)+\varphi^{\prime}(x, 3 x,-x)
\end{aligned}
$$

for all $x \in V \backslash\{0\}$. Replacing $x$ by $x / 2$ and dividing it by 2 in the above inequality, we obtain

$$
\left\|G(x)-\frac{G(2 x)}{2}\right\| \leq \frac{M(x)}{2}
$$


for all $x \in V \backslash\{0\}$. Applying Lemma 2.1, we obtain

$$
\left\|G(x)-\lim _{n \rightarrow \infty} \frac{G\left(2^{n} x\right)}{2^{n}}\right\| \leq \widehat{M}(x)
$$

for all $x \in V \backslash\{0\}$. Similarly we have

$$
\left\|H(x)-\lim _{n \rightarrow \infty} \frac{H\left(2^{n} x\right)}{2^{n}}\right\| \leq \widehat{M}^{\prime}(x)
$$

for all $x \in V \backslash\{0\}$. From (2.67), we get

$$
\lim _{n \rightarrow \infty} \frac{G\left(2^{n} x\right)}{2^{n}}=\lim _{n \rightarrow \infty} \frac{H\left(2^{n} x\right)}{2^{n}}
$$

for all $x \in V$ and we can define a function $A: V \rightarrow X$ by

$$
A(x)=\lim _{n \rightarrow \infty} \frac{G\left(2^{n} x\right)}{2^{n}}=\lim _{n \rightarrow \infty} \frac{H\left(2^{n} x\right)}{2^{n}}
$$

for all $x \in V \backslash\{0\}$. It follows from (2.66) and (2.70) that

$$
\begin{aligned}
\|F(x)-A(x)\|= & \left\|F(x)-H\left(\frac{x}{4}\right)+F\left(\frac{x}{2}\right)-G\left(\frac{x}{2}\right)-H\left(\frac{3 x}{4}\right)\right\| \\
& +\left\|H\left(\frac{3 x}{4}\right)-F\left(\frac{x}{2}\right)-G\left(\frac{x}{2}\right)+H\left(\frac{x}{4}\right)\right\|+\left\|2 G\left(\frac{x}{2}\right)-2 A\left(\frac{x}{2}\right)\right\| \\
& \leq \varphi^{\prime}\left(\frac{x}{4}, \frac{x}{4},-\frac{x}{2}\right)+\varphi^{\prime}\left(\frac{x}{4}, \frac{x}{4}, \frac{x}{2}\right)+2 \widehat{M}\left(\frac{x}{2}\right)
\end{aligned}
$$

for all $x \in V \backslash\{0\}$. Replacing $x$ by $2^{n} x$, dividing it by $2^{n}$ in the above inequality and taking the limit in the resulted inequality as $n \rightarrow \infty$, we obtain

$$
\lim _{n \rightarrow \infty} \frac{F\left(2^{n} x\right)}{2^{n}}=A(x)
$$

for all $x \in V \backslash\{0\}$. From (2.73) and (2.75), we have

$$
A(x+y+z)+A(x-y)+A(x-z)-A(x-y-z)-A(x+y)-A(x+z)=0
$$

for all $x, y, z \in V \backslash\{0\}$. Replace $y$ and $z$ by $2 y$ and $x$ in (2.76) to obtain

$$
A(2 x+2 y)+A(x-2 y)+A(2 y)-A(x+2 y)-A(2 x)=0
$$

for all $x, y, z \in V \backslash\{0\}$. Replace $y$ and $z$ by $-2 y$ and $x$ in (2.76) to get

$$
A(2 x-2 y)+A(x+2 y)-A(2 y)-A(x-2 y)-A(2 x)=0
$$


for all $x, y \in V \backslash\{0\}$. Since $A(0)=0$ and $A(2 x)=2 A(x)$, using the above two equalities, we have

$$
A(x-y)+A(x+y)-A(2 x)=0
$$

for all $x, y \in V$. Hence, $A$ is an additive function.

Let the functions $F^{\prime}, G^{\prime}, H^{\prime}: V \rightarrow X$ be defined by

$$
F^{\prime}(x)=\frac{1}{2}\left[f_{1}(x)-f_{4}(x)\right], \quad G^{\prime}(x)=\frac{1}{2}\left[f_{2}(x)-f_{5}(x)\right], \quad H^{\prime}(x)=\frac{1}{2}\left[f_{3}(x)-f_{6}(x)\right]
$$

for all $x, y, z \in V$. From (2.59) and (2.64), we have

$$
\left\|F^{\prime}(x+y+z)+G^{\prime}(x-y)+H^{\prime}(x-z)+F^{\prime}(x-y-z)+G^{\prime}(x+y)+H^{\prime}(x+z)\right\| \leq \varphi^{\prime}(x, y, z)
$$

for all $x, y, z \in V \backslash\{0\}$. It follows from (2.81) that

$$
\begin{aligned}
\left\|G^{\prime}(x)-\frac{G^{\prime}(2 x)}{2}\right\| \leq & \frac{1}{2}\left\|F^{\prime}\left(\frac{3 x}{2}\right)-F^{\prime}\left(\frac{x}{2}\right)-G^{\prime}(x)+G^{\prime}(2 x)+H^{\prime}(x)\right\| \\
& +\frac{1}{2}\left\|F^{\prime}\left(\frac{3 x}{2}\right)-F^{\prime}\left(\frac{x}{2}\right)+G^{\prime}(x)+H^{\prime}(x)\right\| \\
& \leq \frac{1}{2} \varphi^{\prime}\left(\frac{x}{2}, \frac{3 x}{2},-\frac{x}{2}\right)+\frac{1}{2} \varphi^{\prime}\left(\frac{x}{2}, \frac{x}{2}, \frac{x}{2}\right)
\end{aligned}
$$

for all $x \in V \backslash\{0\}$. Applying Lemma 2.1, we obtain an odd function $A_{1}: V \rightarrow X$ defined by

$$
A_{1}(x)=\lim _{n \rightarrow \infty} \frac{G^{\prime}\left(2^{n} x\right)}{2^{n}}
$$

and the inequality

$$
\left\|G^{\prime}(x)-A_{1}(x)\right\| \leq \widehat{\varphi}^{\prime}\left(\frac{x}{2}, \frac{3 x}{2},-\frac{x}{2}\right)+\widehat{\varphi}^{\prime}\left(\frac{x}{2}, \frac{x}{2}, \frac{x}{2}\right)
$$

holds for all $x \in V \backslash\{0\}$. Similarly we have an odd function $A_{2}: V \rightarrow X$ defined by

$$
A_{2}(x)=\lim _{n \rightarrow \infty} \frac{H^{\prime}\left(2^{n} x\right)}{2^{n}}
$$

for all $x \in V$ and the inequality

$$
\left\|H^{\prime}(x)-A_{2}(x)\right\| \leq \widehat{\varphi}^{\prime}\left(\frac{x}{2},-\frac{x}{2}, \frac{3 x}{2}\right)+\widehat{\varphi}^{\prime}\left(\frac{x}{2}, \frac{x}{2}, \frac{x}{2}\right)
$$

for all $x \in V \backslash\{0\}$. Replace $x, y, z$ by $x, x,-x$ in (2.81) to get

$$
\left\|2 F^{\prime}(x)+G^{\prime}(2 x)+H^{\prime}(2 x)\right\| \leq \varphi^{\prime}(x, x,-x)
$$


for all $x \in V \backslash\{0\}$. Replacing $x$ by $2^{n-1} x$ and dividing it by $2^{n}$ in the above inequality, we obtain

$$
\left\|\frac{2 F^{\prime}\left(2^{n-1} x\right)+G^{\prime}\left(2^{n} x\right)+H^{\prime}\left(2^{n} x\right)}{2^{n}}\right\| \leq \frac{\varphi^{\prime}\left(2^{n} x, 2^{n} x,-2^{n} x\right)}{2^{n}}
$$

for all $x \in V \backslash\{0\}$. Taking the limit in the above inequality as $n \rightarrow \infty$, we have

$$
\lim _{n \rightarrow \infty} \frac{F^{\prime}\left(2^{n} x\right)}{2^{n}}=-A_{1}(x)-A_{2}(x)
$$

for all $x \in V \backslash\{0\}$. It follows from (2.81) that

$$
\begin{aligned}
\left\|F^{\prime}(x)-\frac{F^{\prime}(2 x)}{2}\right\| \leq & \frac{1}{2}\left\|F^{\prime}(2 x)+G^{\prime}(0)-H^{\prime}\left(\frac{x}{2}\right)-F^{\prime}(x)+G^{\prime}(x)+H^{\prime}\left(\frac{3 x}{2}\right)\right\| \\
& +\frac{1}{2}\left\|F^{\prime}(x)+G^{\prime}(x)-H^{\prime}\left(\frac{x}{2}\right)+F^{\prime}(0)+G^{\prime}(0)+H^{\prime}\left(\frac{3 x}{2}\right)\right\| \\
& \leq \frac{1}{2}\left[\varphi^{\prime}\left(\frac{x}{2}, \frac{x}{2}, x\right)+\varphi^{\prime}\left(\frac{x}{2}, \frac{x}{2},-x\right)\right]
\end{aligned}
$$

for all $x \in V \backslash\{0\}$. Applying Lemma 2.1 and (2.89), we have

$$
\left\|F^{\prime}(x)+A_{1}(x)+A_{2}(x)\right\| \leq \widehat{\varphi}^{\prime}\left(\frac{x}{2}, \frac{x}{2}, x\right)+\widehat{\varphi}^{\prime}\left(\frac{x}{2}, \frac{x}{2},-x\right)
$$

for all $x \in V \backslash\{0\}$. From (2.81), (2.83), (2.85), and (2.89), we have

$$
\begin{gathered}
-A_{1}(x+y+z)-A_{2}(x+y+z)+A_{1}(x-y)+A_{2}(x-z)-A_{1}(x-y-z) \\
-A_{2}(x-y-z)+A_{1}(x+y)+A_{2}(x+z)=0
\end{gathered}
$$

for all $x, y, z \in V \backslash\{0\}$. Replace $y$ and $z$ by $2 y$ and $x$ in (2.92) to get

$$
-A_{1}(2 x+2 y)-A_{2}(2 x+2 y)+A_{1}(x-2 y)+A_{1}(2 y)+A_{2}(2 y)+A_{2}(2 x)+A_{1}(x+2 y)=0
$$

for all $x, y \in V \backslash\{0\}$. Replace $y$ and $z$ by $x$ and $2 y$ in (2.92) to get

$$
-A_{1}(2 x+2 y)-A_{2}(2 x+2 y)+A_{2}(x-2 y)+A_{1}(2 y)+A_{2}(2 y)+A_{1}(2 x)+A_{2}(x+2 y)=0
$$

for all $x, y \in V \backslash\{0\}$. From the above two equalities, we get

$$
\left(A_{1}-A_{2}\right)(x-2 y)-\left(A_{1}-A_{2}\right)(2 x)+\left(A_{1}-A_{2}\right)(x+2 y)=0
$$

for all $x, y \in V \backslash\{0\}$. Since $A(0)=0$, we have

$$
\left(A_{1}-A_{2}\right)(x-2 y)-\left(A_{1}-A_{2}\right)(2 x)+\left(A_{1}-A_{2}\right)(x+2 y)=0
$$


for all $x, y \in V$. Hence $A_{1}-A_{2}$ is additive, that is,

$$
\left(A_{1}-A_{2}\right)(x+y)=\left(A_{1}-A_{2}\right)(x)+\left(A_{1}-A_{2}\right)(y)
$$

for all $x, y \in V$. Replace $z$ by $-y$ in (2.92) to obtain

$$
-A_{1}(x)-A_{2}(x)+A_{1}(x-y)+A_{2}(x+y)-A_{1}(x)-A_{2}(x)+A_{1}(x+y)+A_{2}(x-y)=0
$$

for all $x, y \in V \backslash\{0\}$. Since $A_{1}-A_{2}$ is additive, we have

$$
A_{2}(2 x)-A_{2}(x+y)-A_{2}(x-y)=A_{1}(2 x)-A_{1}(x+y)-A_{1}(x-y)
$$

for all $x, y \in V \backslash\{0\}$. From this and (2.98), we get

$$
-A_{1}(4 x)+2 A_{1}(x-y)+2 A_{1}(x+y)=0
$$

for all $x, y \in V \backslash\{0\}$. From this and $A_{1}(0)=0$, we have

$$
A_{1}(x+y)=A_{1}(x)+A_{1}(y)
$$

for all $x, y \in V$. Since $A_{1}$ and $A_{1}-A_{2}$ are additive, $A_{2}$ is additive.

From (2.74), (2.91), and the definitions of $F, F^{\prime}$, we have

$$
\begin{aligned}
\left\|f_{1}(x)-A(x)+A_{1}(x)+A_{2}(x)\right\| & \leq\|F(x)-A(x)\|+\left\|F^{\prime}(x)+A_{1}(x)+A_{2}(x)\right\| \\
& \leq \varphi^{\prime}\left(\frac{x}{4}, \frac{x}{4},-\frac{x}{2}\right)+\varphi^{\prime}\left(\frac{x}{4}, \frac{x}{4}, \frac{x}{2}\right)+2 \widehat{M}\left(\frac{x}{2}\right) \\
& +\widehat{\varphi}^{\prime}\left(\frac{x}{2}, \frac{x}{2}, x\right)+\widehat{\varphi}^{\prime}\left(\frac{x}{2}, \frac{x}{2},-x\right)
\end{aligned}
$$

for all $x \in V \backslash\{0\}$. The rest of inequalities in (2.60) can be shown by the similar method.

Theorem 2.6. Let $\varphi: V \backslash\{0\} \times V \backslash\{0\} \times V \backslash\{0\} \rightarrow[0, \infty)$ be a function such that

$$
\widehat{\varphi}(x, y, z):=\sum_{l=0}^{\infty} 2^{l} \varphi\left(\frac{x}{2^{l+1}}, \frac{y}{2^{l+1}}, \frac{z}{2^{l+1}}\right)<\infty
$$

holds for all $x, y, z \in V \backslash\{0\}$. If the odd functions $f_{1}, f_{2}, f_{3}, f_{4}, f_{5}, f_{6}: V \rightarrow X$ satisfy inequalities (2.59) for all $x, y, z \in V \backslash\{0\}$, then there exist exactly three additive functions $A, A_{1}, A_{2}: V \rightarrow X$ satisfying the inequalities (2.60) for all $x \in V \backslash\{0\}$, where

$$
\begin{aligned}
\widehat{M}(x):= & \sum_{l=0}^{\infty} 2^{l} M\left(\frac{x}{2^{l+1}}\right), \quad \widehat{M}^{\prime}(x):=\sum_{l=0}^{\infty} 2^{l} M^{\prime}\left(\frac{x}{2^{l+1}}\right), \\
& \widehat{\varphi}^{\prime}(x, y, z):=\sum_{l=0}^{\infty} 2^{l} \varphi^{\prime}\left(\frac{x}{2^{l+1}}, \frac{y}{2^{l+1}}, \frac{z}{2^{l+1}}\right) .
\end{aligned}
$$

Moreover, the functions $A, A_{1}, A_{2}$ are given by

$$
\begin{aligned}
& A(x)=\lim _{n \rightarrow \infty} 2^{n-2}\left(f_{1}\left(\frac{x}{2^{n}}\right)+f_{4}\left(\frac{x}{2^{n}}\right)-f_{1}\left(-\frac{x}{2^{n}}\right)-f_{4}\left(-\frac{x}{2^{n}}\right)\right), \\
& A_{1}(x)=\lim _{n \rightarrow \infty} 2^{n-2}\left(f_{2}\left(\frac{x}{2^{n}}\right)-f_{5}\left(\frac{x}{2^{n}}\right)-f_{2}\left(-\frac{x}{2^{n}}\right)+f_{5}\left(-\frac{x}{2^{n}}\right)\right), \\
& A_{2}(x)=\lim _{n \rightarrow \infty} 2^{n-2}\left(f_{3}\left(\frac{x}{2^{n}}\right)-f_{6}\left(\frac{x}{2^{n}}\right)-f_{3}\left(-\frac{x}{2^{n}}\right)+f_{6}\left(-\frac{x}{2^{n}}\right)\right)
\end{aligned}
$$

for all $x \in V$. 
Proof. The proof is similar to that of Theorem 2.5 . inequality.

Applying Theorems 2.5 and 2.6, we get the following corollary in the sense of Rassias

Corollary 2.7. Let $p \neq 1$. If the odd functions $f_{i}: V \rightarrow X, i=1,2, \ldots, 6$, satisfy

$$
\begin{aligned}
& \left\|f_{1}(x+y+z)+f_{2}(x-y)+f_{3}(x-z)-f_{4}(x-y-z)-f_{5}(x+y)-f_{6}(x+z)\right\| \\
& \quad \leq \varepsilon\left(\|x\|^{p}+\|y\|^{p}+\|z\|^{p}\right)
\end{aligned}
$$

for all $x, y, z \in V \backslash\{0\}$.

Then there exist exactly three additive functions $A, A_{1}, A_{2}: V \rightarrow X$ satisfying

$$
\begin{aligned}
\left\|f_{1}(x)-f_{1}(0)-A(x)+A_{1}(x)+A_{2}(x)\right\| & \leq\left[\frac{2}{2^{p}}+\frac{4}{4^{p}}+\frac{2\left(3^{p}+11\right)+4 \cdot 2^{p}+2 \cdot 4^{p}}{4^{p}\left|2^{p}-2\right|}\right] \cdot \varepsilon \cdot\|x\|^{p}, \\
\left\|f_{2}(x)-f_{2}(0)-A(x)-A_{1}(x)\right\| & \leq \frac{2\left(3^{p}+8\right)}{2^{p}\left|2^{p}-2\right|} \cdot \varepsilon \cdot\|x\|^{p}, \\
\left\|f_{3}(x)-f_{3}(0)-A(x)-A_{2}(x)\right\| & \leq \frac{2\left(3^{p}+8\right)}{2^{p}\left|2^{p}-2\right|} \cdot \varepsilon \cdot\|x\|^{p}, \\
\left\|f_{4}(x)-f_{4}(0)-A(x)-A_{1}(x)-A_{2}(x)\right\| & \leq\left[\frac{2}{2^{p}}+\frac{4}{4^{p}}+\frac{2\left(3^{p}+11\right)+4 \cdot 2^{p}+2 \cdot 4^{p}}{4^{p}\left|2^{p}-2\right|}\right] \cdot \varepsilon \cdot\|x\|^{p}, \\
\left\|f_{5}(x)-f_{5}(0)-A(x)+A_{1}(x)\right\| & \leq \frac{2\left(3^{p}+8\right)}{2^{p}\left|2^{p}-2\right|} \cdot \varepsilon \cdot\|x\|^{p}, \\
\left\|f_{6}(x)-f_{6}(0)-A(x)+A_{2}(x)\right\| & \leq \frac{2\left(3^{p}+8\right)}{2^{p}\left|2^{p}-2\right|} \cdot \varepsilon \cdot\|x\|^{p}
\end{aligned}
$$

for all $x \in V \backslash\{0\}$. Moreover, the functions $A, A_{1}, A_{2}$ are given by

$$
\begin{aligned}
& A(x)= \begin{cases}\lim _{n \rightarrow \infty} \frac{f_{1}\left(2^{n} x\right)+f_{4}\left(2^{n} x\right)-f_{1}\left(-2^{n} x\right)-f_{4}\left(-2^{n} x\right)}{2^{n+2}}, & \text { if } p<1, \\
\lim _{n \rightarrow \infty} 2^{n-2}\left(f_{1}\left(\frac{x}{2^{n}}\right)+f_{4}\left(\frac{x}{2^{n}}\right)-f_{1}\left(-\frac{x}{2^{n}}\right)-f_{4}\left(-\frac{x}{2^{n}}\right)\right), & \text { if } p>1,\end{cases} \\
& A_{1}(x)= \begin{cases}\lim _{n \rightarrow \infty} \frac{f_{2}\left(2^{n} x\right)-f_{5}\left(2^{n} x\right)-f_{2}\left(-2^{n} x\right)+f_{5}\left(-2^{n} x\right)}{2^{n+2}}, & \text { if } p<1, \\
\lim _{n \rightarrow \infty} 2^{n-2}\left(f_{2}\left(\frac{x}{2^{n}}\right)-f_{5}\left(\frac{x}{2^{n}}\right)-f_{2}\left(-\frac{x}{2^{n}}\right)+f_{5}\left(-\frac{x}{2^{n}}\right)\right), & \text { if } p>1,\end{cases} \\
& A_{2}(x)= \begin{cases}\lim _{n \rightarrow \infty} \frac{f_{3}\left(2^{n} x\right)-f_{6}\left(2^{n} x\right)-f_{3}\left(-2^{n} x\right)+f_{6}\left(-2^{n} x\right)}{2^{n+2}}, & \text { if } p<1, \\
\lim _{n \rightarrow \infty} 2^{n-2}\left(f_{3}\left(\frac{x}{2^{n}}\right)-f_{6}\left(\frac{x}{2^{n}}\right)-f_{3}\left(-\frac{x}{2^{n}}\right)+f_{6}\left(-\frac{x}{2^{n}}\right)\right), & \text { if } p>1\end{cases}
\end{aligned}
$$

for all $x \in V$. 
Kil-Woung Jun et al.

Proof. Apply Theorem 2.5 for $p<1$ and Theorem 2.6 for $p>1$.

We establish the following theorem for the general case from Theorems 2.2 and 2.5.

Theorem 2.8. Let $\varphi: V \backslash\{0\} \times V \backslash\{0\} \times V \backslash\{0\} \rightarrow[0, \infty)$ be a function that satisfies conditions (a) and (b). Suppose that the functions $f_{i}: V \rightarrow X, i=1,2, \ldots, 6$, satisfy the inequality

$$
\left\|f_{1}(x+y+z)+f_{2}(x-y)+f_{3}(x-z)-f_{4}(x-y-z)-f_{5}(x+y)-f_{6}(x+z)\right\| \leq \varphi(x, y, z)
$$

for all $x, y, z \in V \backslash\{0\}$. Then there exist exactly one quadratic function $Q: V \rightarrow X$ and exactly three additive functions $A, A_{1}, A_{2}: V \rightarrow X$ satisfying

$$
\begin{aligned}
& \left\|f_{1}(x)-f_{1}(0)-Q(x)-A(x)+A_{1}(x)+A_{2}(x)\right\| \\
& \leq \frac{1}{2}\left[\varphi_{e}^{\prime}\left(\frac{x}{2}, \frac{3}{2} x,-x\right)+\varphi_{e}^{\prime}\left(\frac{x}{2}, \frac{x}{2},-x\right)\right]+2 \varphi_{e}^{\prime}\left(\frac{x}{4}, \frac{x}{4},-\frac{x}{2}\right)+2 \varphi_{e}^{\prime}\left(\frac{x}{4}, \frac{x}{4}, \frac{x}{2}\right) \\
& +\frac{1}{2} \widetilde{M}_{e}(2 x)+\widetilde{M}_{e}(x)+2 \widehat{M}_{e}\left(\frac{x}{2}\right)+\widehat{\varphi}_{e}^{\prime}\left(\frac{x}{2}, \frac{x}{2}, x\right)+\widehat{\varphi}_{e}^{\prime}\left(\frac{x}{2},-\frac{x}{2}, x\right), \\
& \left\|f_{2}(x)-f_{2}(0)-Q(x)-A(x)-A_{1}(x)\right\| \\
& \leq \widetilde{M}_{e}(x)+\varphi_{e}^{\prime}\left(\frac{x}{4}, \frac{3 x}{4},-\frac{x}{4}\right)+\varphi_{e}^{\prime}\left(\frac{x}{4}, \frac{x}{4}, \frac{x}{4}\right)+\widehat{M}_{e}(x)+\widehat{\varphi}_{e}^{\prime}\left(\frac{x}{2}, \frac{3 x}{2},-\frac{x}{2}\right)+\widehat{\varphi}_{e}^{\prime}\left(\frac{x}{2}, \frac{x}{2}, \frac{x}{2}\right), \\
& \left\|f_{3}(x)-f_{3}(0)-Q(x)-A(x)-A_{2}(x)\right\| \\
& \leq \widetilde{M}_{e}^{\prime}(x)+\varphi_{e}^{\prime}\left(\frac{x}{4}, \frac{x}{4},-\frac{3 x}{4}\right)+\varphi_{e}^{\prime}\left(\frac{x}{4}, \frac{x}{4}, \frac{x}{4}\right)+\widehat{M}_{e}^{\prime}(x)+\widehat{\varphi}_{e}^{\prime}\left(\frac{x}{2}, \frac{x}{2},-\frac{3 x}{2}\right)+\widehat{\varphi}_{e}^{\prime}\left(\frac{x}{2}, \frac{x}{2}, \frac{x}{2}\right), \\
& \left\|f_{4}(x)-f_{4}(0)-Q(x)-A(x)-A_{1}(x)-A_{2}(x)\right\| \\
& \leq \frac{1}{2}\left[\varphi_{e}^{\prime}\left(\frac{x}{2}, \frac{3}{2} x,-x\right)+\varphi_{e}^{\prime}\left(\frac{x}{2}, \frac{x}{2},-x\right)\right]+2 \varphi_{e}^{\prime}\left(\frac{x}{4}, \frac{x}{4},-\frac{x}{2}\right)+2 \varphi_{e}^{\prime}\left(\frac{x}{4}, \frac{x}{4}, \frac{x}{2}\right) \\
& +\frac{1}{2} \widetilde{M}_{e}(2 x)+\widetilde{M}_{e}(x)+2 \widehat{M}_{e}\left(\frac{x}{2}\right)+\widehat{\varphi}_{e}^{\prime}\left(\frac{x}{2}, \frac{x}{2}, x\right)+\widehat{\varphi}_{e}^{\prime}\left(\frac{x}{2},-\frac{x}{2}, x\right), \\
& \left\|f_{5}(x)-f_{5}(0)-Q(x)-A(x)+A_{1}(x)\right\| \\
& \leq \widetilde{M}_{e}(x)+\varphi_{e}^{\prime}\left(\frac{x}{4}, \frac{3 x}{4},-\frac{x}{4}\right)+\varphi_{e}^{\prime}\left(\frac{x}{4}, \frac{x}{4}, \frac{x}{4}\right)+\widehat{M}_{e}(x)+\widehat{\varphi}_{e}^{\prime}\left(\frac{x}{2}, \frac{3 x}{2},-\frac{x}{2}\right)+\widehat{\varphi}_{e}^{\prime}\left(\frac{x}{2}, \frac{x}{2}, \frac{x}{2}\right), \\
& \left\|f_{6}(x)-f_{6}(0)-Q(x)-A(x)+A_{2}(x)\right\| \\
& \leq \widetilde{M}^{\prime}(x)+\varphi_{e}^{\prime}\left(\frac{x}{4}, \frac{x}{4},-\frac{3 x}{4}\right)+\varphi_{e}^{\prime}\left(\frac{x}{4}, \frac{x}{4}, \frac{x}{4}\right)+\widehat{M}_{e}^{\prime}(x)+\widehat{\varphi}_{e}^{\prime}\left(\frac{x}{2}, \frac{x}{2},-\frac{3 x}{2}\right)+\widehat{\varphi}_{e}^{\prime}\left(\frac{x}{2}, \frac{x}{2}, \frac{x}{2}\right)
\end{aligned}
$$


for all $x \in V \backslash\{0\}$, where

$$
\begin{aligned}
\widetilde{M}_{e}(x):= & \sum_{l=0}^{\infty} \frac{1}{4^{l+1}} M_{e}\left(2^{l} x\right), \quad \widetilde{M}_{e}^{\prime}(x):=\sum_{l=0}^{\infty} \frac{1}{4^{l+1}} M_{e}^{\prime}\left(2^{l} x\right), \\
\widehat{M}_{e}:= & \sum_{l=0}^{\infty} \frac{1}{2^{l+1}} M_{e}\left(2^{l} x\right), \quad \widehat{M}_{e}^{\prime}:=\sum_{l=0}^{\infty} \frac{1}{2^{l+1}} M_{e}\left(2^{l} x\right), \\
& \widehat{\varphi}_{e}^{\prime}(x, y, z):=\sum_{l=0}^{\infty} \frac{1}{2^{l+1}} \varphi_{e}^{\prime}\left(2^{l} x, 2^{l} y, 2^{l} z\right)
\end{aligned}
$$

for all $x \in V \backslash\{0\}$. Moreover, the function $Q$ is given by

$$
Q(x)=\lim _{n \rightarrow \infty} \frac{f_{k}\left(2^{n} x\right)+f_{k}\left(-2^{n} x\right)}{2 \cdot 4^{n}}
$$

for $i=1,2,3,4,5,6$ and the functions $A, A_{1}, A_{2}$ are given by

$$
\begin{aligned}
& A(x)=\lim _{n \rightarrow \infty} \frac{f_{1}\left(2^{n} x\right)+f_{4}\left(2^{n} x\right)-f_{1}\left(-2^{n} x\right)-f_{4}\left(-2^{n} x\right)}{2^{n+2}}, \\
& A_{1}(x)=\lim _{n \rightarrow \infty} \frac{f_{2}\left(2^{n} x\right)-f_{5}\left(2^{n} x\right)-f_{2}\left(-2^{n} x\right)+f_{5}\left(-2^{n} x\right)}{2^{n+2}}, \\
& A_{2}(x)=\lim _{n \rightarrow \infty} \frac{f_{3}\left(2^{n} x\right)-f_{6}\left(2^{n} x\right)-f_{3}\left(-2^{n} x\right)+f_{6}\left(-2^{n} x\right)}{2^{n+2}}
\end{aligned}
$$

for all, $x \in V$.

Proof. From (2.108), we obtain

$$
\begin{aligned}
& \left\|f_{1}(-x-y-z)+f_{2}(-x+y)+f_{3}(-x+z)-f_{4}(-x+y+z)-f_{5}(-x-y)-f_{6}(-x-z)\right\| \\
& \quad \leq \varphi(-x,-y,-z)
\end{aligned}
$$

for all $x, y, z \in V \backslash\{0\}$. From (2.108) and this inequality, one gets

$$
\begin{aligned}
& \left\|f_{1 e}(x+y+z)+f_{2 e}(x-y)+f_{3 e}(x-z)-f_{4 e}(x-y-z)-f_{5 e}(x+y)-f_{6 e}(x+z)\right\| \leq \varphi_{e}(x, y, z), \\
& \left\|f_{1 o}(x+y+z)+f_{2 o}(x-y)+f_{3 o}(x-z)-f_{4 o}(x-y-z)-f_{5 o}(x+y)-f_{6 o}(x+z)\right\| \leq \varphi_{e}(x, y, z)
\end{aligned}
$$

for all $x, y, z \in V \backslash\{0\}$, where $f_{k e}(x)=\left(f_{k}(x)+f_{k}(-x)\right) / 2, f_{k o}(x)=\left(f_{k}(x)-f_{k}(-x)\right) / 2$ for all $x \in V \backslash\{0\}, k=1,2,3,4,5,6$. Since $f_{k e}$ is an even function, $f_{k o}$ is an odd function, and $f_{k}=f_{k e}+f_{k o}$, we can apply Theorems 2.2 and 2.5 to get the desired result.

We establish the following theorem for the general case from Theorems 2.2 and 2.6.

Theorem 2.9. Let $\varphi: V \backslash\{0\} \times V \backslash\{0\} \times V \backslash\{0\} \rightarrow[0, \infty)$ be a function that satisfies conditions (a) and ( $\left.b^{\prime}\right)$. If the functions $f_{1}, f_{2}, f_{3}, f_{4}, f_{5}, f_{6}: V \rightarrow X$ satisfy inequalities (2.108) for all $x, y, z \in$ $V \backslash\{0\}$, then there exist exactly one quadratic function $Q: V \rightarrow X$ and exactly three additive functions 
$A, A_{1}, A_{2}: V \rightarrow X$ satisfying the inequalities in Theorem 2.8 for all $x \in V \backslash\{0\}$, where $\widetilde{M}_{e}, \widetilde{M}_{e}^{\prime}$ are as in Theorem 2.8 and

$$
\begin{aligned}
\widehat{M}_{e}(x):= & \sum_{l=0}^{\infty} 2^{l} M_{e}\left(\frac{x}{2^{l+1}}\right), \quad \widehat{M}_{e}^{\prime}(x):=\sum_{l=0}^{\infty} 2^{l} M_{e}^{\prime}\left(\frac{x}{2^{l+1}}\right), \\
& \widehat{\varphi}_{e}^{\prime}(x, y, z):=\sum_{l=0}^{\infty} 2^{l} \varphi_{e}^{\prime}\left(\frac{x}{2^{l+1}}, \frac{y}{2^{l+1}}, \frac{z}{2^{l+1}}\right)
\end{aligned}
$$

for all $x \in V \backslash\{0\}$. Moreover, the function $Q$ is given by (2.111) and the functions $A, A_{1}, A_{2}$ are given by

$$
\begin{aligned}
& A(x)=\lim _{n \rightarrow \infty} 2^{n-2}\left(f_{1}\left(\frac{x}{2^{n}}\right)+f_{4}\left(\frac{x}{2^{n}}\right)-f_{1}\left(-\frac{x}{2^{n}}\right)-f_{4}\left(-\frac{x}{2^{n}}\right)\right), \\
& A_{1}(x)=\lim _{n \rightarrow \infty} 2^{n-2}\left(f_{2}\left(\frac{x}{2^{n}}\right)-f_{5}\left(\frac{x}{2^{n}}\right)-f_{2}\left(-\frac{x}{2^{n}}\right)+f_{5}\left(-\frac{x}{2^{n}}\right)\right), \\
& A_{2}(x)=\lim _{n \rightarrow \infty} 2^{n-2}\left(f_{3}\left(\frac{x}{2^{n}}\right)-f_{6}\left(\frac{x}{2^{n}}\right)-f_{3}\left(-\frac{x}{2^{n}}\right)+f_{6}\left(-\frac{x}{2^{n}}\right)\right)
\end{aligned}
$$

for all $x \in V$.

We establish the following theorem for the general case from Theorems 2.3 and 2.6.

Theorem 2.10. Let $\varphi: V \backslash\{0\} \times V \backslash\{0\} \times V \backslash\{0\} \rightarrow[0, \infty)$ be a function that satisfies conditions $\left(a^{\prime}\right)$ and $\left(b^{\prime}\right)$. If the functions $f_{1}, f_{2}, f_{3}, f_{4}, f_{5}, f_{6}: V \rightarrow X$ satisfy inequalities (2.108) for all $x, y, z \in$ $V \backslash\{0\}$, then there exist exactly one quadratic function $Q: V \rightarrow X$ and exactly three additive functions $A, A_{1}, A_{2}: V \rightarrow X$ satisfying the inequalities in Theorem 2.8 for all $x \in V \backslash\{0\}$, where $\widehat{M}_{e}, \widehat{M}_{e}^{\prime}, \widehat{\varphi}_{e}^{\prime}$ are as in Theorem 2.9 and

$$
\widetilde{M}_{e}(x):=\sum_{l=0}^{\infty} 4^{l} M_{e}\left(\frac{x}{2^{l+1}}\right), \quad \widetilde{M}_{e}^{\prime}(x):=\sum_{l=0}^{\infty} 4^{l} M_{e}^{\prime}\left(\frac{x}{2^{l+1}}\right)
$$

for all $x \in V \backslash\{0\}$. Moreover, the function $Q$ is given by

$$
Q(x)=\lim _{n \rightarrow \infty} 2 \cdot 4^{n-1}\left(f_{k}\left(2^{-n} x\right)+f_{k}\left(-2^{-n} x\right)-2 f_{k}(0)\right)
$$

for $i=1,2,3,4,5,6$ and the functions $A, A_{1}, A_{2}$ are given by (2.116) for all $x \in V$.

Corollary 2.11. Let $p \neq 1,2$ and $\varepsilon>0$. Suppose that the functions $f_{i}: V \rightarrow X, i=1,2, \ldots, 6$, satisfy

$$
\begin{aligned}
& \left\|f_{1}(x+y+z)+f_{2}(x-y)+f_{3}(x-z)-f_{4}(x-y-z)-f_{5}(x+y)-f_{6}(x+z)\right\| \\
& \quad \leq \varepsilon\left(\|x\|^{p}+\|y\|^{p}+\|z\|^{p}\right)
\end{aligned}
$$

for all $x, y, z \in V \backslash\{0\}$. 
Then there exist exactly one quadratic function $Q: V \rightarrow X$ and three additive functions $A, A_{1}, A_{2}: V \rightarrow X$ satisfying

$$
\begin{aligned}
& \left\|f_{1}(x)-f_{1}(0)-Q(x)-A(x)+A_{1}(x)+A_{2}(x)\right\| \\
& \leq\left[\frac{\left(3^{p}+11\right)\left(2^{p}+2\right)}{2 \cdot 2^{p}\left|2^{p}-4\right|}+\frac{11+3^{p}}{2 \cdot 2^{p}}+1+\frac{8}{4^{p}}+\frac{2\left(3^{p}+11\right)+4 \cdot 2^{p}+2 \cdot 4^{p}}{4^{p}\left|2^{p}-2\right|}\right] \cdot \varepsilon \cdot\|x\|^{p}, \\
& \left\|f_{2}(x)-f_{2}(0)-Q(x)-A(x)-A_{1}(x)\right\| \leq\left[\frac{\left(3^{p}+11\right)}{2^{p}\left|2^{p}-4\right|}+\frac{3^{p}+5}{4^{p}}+\frac{2\left(3^{p}+8\right)}{2^{p}\left|2^{p}-2\right|}\right] \cdot \varepsilon \cdot\|x\|^{p}, \\
& \left\|f_{3}(x)-f_{3}(0)-Q(x)-A(x)-A_{2}(x)\right\| \leq\left[\frac{\left(3^{p}+11\right)}{2^{p}\left|2^{p}-4\right|}+\frac{3^{p}+5}{4^{p}}+\frac{2\left(3^{p}+8\right)}{\left.2^{p}\left|2^{p}-2\right|\right] \cdot \varepsilon \cdot\|x\|^{p},}\right. \\
& \left\|f_{4}(x)-f_{4}(0)-Q(x)-A(x)-A_{1}(x)-A_{2}(x)\right\| \\
& \leq\left[\frac{\left(3^{p}+11\right)\left(2^{p}+2\right)}{2 \cdot 2^{p}\left|2^{p}-4\right|}+\frac{11+3^{p}}{2 \cdot 2^{p}}+1+\frac{8}{4^{p}}+\frac{2\left(3^{p}+11\right)+4 \cdot 2^{p}+2 \cdot 4^{p}}{4^{p}\left|2^{p}-2\right|}\right] \cdot \varepsilon \cdot\|x\|^{p} \\
& \left\|f_{5}(x)-f_{5}(0)-Q(x)-A(x)+A_{1}(x)\right\| \leq\left[\frac{\left(3^{p}+11\right)}{2^{p}\left|2^{p}-4\right|}+\frac{3^{p}+5}{4^{p}}+\frac{2\left(3^{p}+8\right)}{2^{p}\left|2^{p}-2\right|}\right] \cdot \varepsilon \cdot\|x\|^{p}, \\
& \left\|f_{6}(x)-f_{6}(0)-Q(x)-A(x)+A_{2}(x)\right\| \leq\left[\frac{\left(3^{p}+11\right)}{2^{p}\left|2^{p}-4\right|}+\frac{3^{p}+5}{4^{p}}+\frac{2\left(3^{p}+8\right)}{2^{p}\left|2^{p}-2\right|}\right] \cdot \varepsilon \cdot\|x\|^{p}
\end{aligned}
$$

for all $x \in V \backslash\{0\}$. Moreover, the function $Q$ is given by (2.111) for $p<2$ and (2.119) for $p>2$ and the functions $A, A_{1}, A_{2}(k=1,2,3)$ are given by (2.112) for $p<1$ and (2.116) for $p>1$.

Corollary 2.12. Let $\varepsilon>0$ be a fixed real number. Suppose that the functions $f_{i}: V \rightarrow X, i=1,2, \ldots, 6$, satisfy

$$
\left\|f_{1}(x+y+z)+f_{2}(x-y)+f_{3}(x-z)-f_{4}(x-y-z)-f_{5}(x+y)-f_{6}(x+z)\right\| \leq \varepsilon
$$

for all $x, y, z \in V \backslash\{0\}$.

Then there exist exactly one quadratic function $Q: V \rightarrow X$ and three additive functions $A, A_{1}, A_{2}: V \rightarrow X$ satisfying

$$
\begin{aligned}
& \left\|f_{1}(x)-f_{1}(0)-Q(x)-A(x)+A_{1}(x)+A_{2}(x)\right\| \leq 17 \varepsilon, \\
& \left\|f_{2}(x)-f_{2}(0)-Q(x)-A(x)-A_{1}(x)\right\| \leq \frac{28}{3} \varepsilon, \\
& \left\|f_{3}(x)-f_{3}(0)-Q(x)-A(x)-A_{2}(x)\right\| \leq \frac{28}{3} \varepsilon, \\
& \left\|f_{4}(x)-f_{4}(0)-Q(x)-A(x)-A_{1}(x)-A_{2}(x)\right\| \leq 17 \varepsilon, \\
& \left\|f_{5}(x)-f_{5}(0)-Q(x)-A(x)+A_{1}(x)\right\| \leq \frac{28}{3} \varepsilon, \\
& \left\|f_{6}(x)-f_{6}(0)-Q(x)-A(x)+A_{2}(x)\right\| \frac{28}{3} \varepsilon
\end{aligned}
$$


for all $x \in V \backslash\{0\}$. Moreover, the function $Q$ is given by (2.111) for $i=1,2,3,4,5,6$ and the functions $A, A_{1}, A_{2}$ are given by (2.112) for all $x \in V$.

Now we obtain the general solution of (1.6) from Corollary 2.12.

Corollary 2.13. Suppose that the functions $f_{i}: V \rightarrow X, i=1,2, \ldots, 6$, satisfy

$$
f_{1}(x+y+z)+f_{2}(x-y)+f_{3}(x-z)-f_{4}(x-y-z)-f_{5}(x+y)-f_{6}(x+z)=0
$$

for all $x, y, z \in V \backslash\{0\}$.

Then there exist exactly one quadratic function $Q: V \rightarrow X$ and three additive functions $A, A_{1}, A_{2}: V \rightarrow X$ satisfying

$$
\begin{aligned}
& f_{1}(x)=Q(x)+A(x)-A_{1}(x)-A_{2}(x)+f_{1}(0), \\
& f_{2}(x)=Q(x)+A(x)+A_{1}(x)+f_{2}(0), \\
& f_{3}(x)=Q(x)+A(x)+A_{2}(x)+f_{3}(0), \\
& f_{4}(x)=Q(x)+A(x)+A_{1}(x)+A_{2}(x)+f_{4}(0), \\
& f_{5}(x)=Q(x)+A(x)-A_{1}(x)+f_{5}(0), \\
& f_{6}(x)=Q(x)+A(x)-A_{2}(x)+f_{6}(0)
\end{aligned}
$$

for all $x \in V$. Moreover, the function $Q$ is given by

$$
Q(x)=\frac{f_{i}(x)+f_{i}(-x)}{2}-f_{i}(0)
$$

for $i=1,2,3,4,5,6$ and the functions $A, A_{1}, A_{2}(k=1,2,3)$ are given by

$$
\begin{aligned}
A(x) & =\frac{f_{1}(x)+f_{4}(x)-f_{1}(-x)-f_{4}(-x)}{4}, \\
A_{1}(x) & =\frac{f_{2}(x)-f_{5}(x)-f_{2}(-x)+f_{5}(-x)}{4}, \\
A_{2}(x) & =\frac{f_{3}(x)-f_{6}(x)-f_{3}(-x)+f_{6}(-x)}{4}
\end{aligned}
$$

for all $x \in V$.

\section{References}

[1] S. M. Ulam, Problems in Modern Mathematics, chapter VI, John Wiley \& Sons, New York, NY, USA, 1960.

[2] D. H. Hyers, "On the stability of the linear functional equation," Proceedings of the National Academy of Sciences of the United States of America, vol. 27, no. 4, pp. 222-224, 1941.

[3] Th. M. Rassias, "On the stability of the linear mapping in Banach spaces," Proceedings of the American Mathematical Society, vol. 72, no. 2, pp. 297-300, 1978.

[4] Th. M. Rassias, "Problem 16; 2, Report of the 27th International Symposium on Functional Equations," Aequationes Mathematicae, vol. 39, no. 2-3, pp. 292-293, 309, 1990. 
[5] Z. Gajda, "On stability of additive mappings," International Journal of Mathematics and Mathematical Sciences, vol. 14, no. 3, pp. 431-434, 1991.

[6] P. Găvruța, "A generalization of the Hyers-Ulam-Rassias stability of approximately additive mappings," Journal of Mathematical Analysis and Applications, vol. 184, no. 3, pp. 431-436, 1994.

[7] D. H. Hyers, G. Isac, and Th. M. Rassias, Stability of Functional Equations in Several Variables, vol. 34 of Progress in Nonlinear Differential Equations and Their Applications, Birkhäuser, Boston, Mass, USA, 1998.

[8] Th. M. Rassias, "On the stability of functional equations in Banach spaces," Journal of Mathematical Analysis and Applications, vol. 251, no. 1, pp. 264-284, 2000.

[9] Th. M. Rassias, "On the stability of functional equations and a problem of Ulam," Acta Applicandae Mathematicae, vol. 62, no. 1, pp. 23-130, 2000.

[10] Th. M. Rassias and P. Šemrl, "On the behavior of mappings which do not satisfy Hyers-Ulam stability," Proceedings of the American Mathematical Society, vol. 114, no. 4, pp. 989-993, 1992.

[11] K.-W. Jun and Y.-H. Lee, "On the Hyers-Ulam-Rassias stability of a Pexiderized quadratic equation. II," in Functional Equations, Inequalities and Applications, pp. 39-65, Kluwer Academic Publishers, Dordrecht, The Netherlands, 2003.

[12] Y.-H. Lee and K.-W. Jun, "A generalization of the Hyers-Ulam-Rassias stability of the Pexider equation," Journal of Mathematical Analysis and Applications, vol. 246, no. 2, pp. 627-638, 2000.

[13] K.-W. Jun, D.-S. Shin, and B.-D. Kim, "On Hyers-Ulam-Rassias stability of the Pexider equation," Journal of Mathematical Analysis and Applications, vol. 239, no. 1, pp. 20-29, 1999.

[14] J. Aczél and J. Dhombres, Functional Equations in Several Variables, vol. 31 of Encyclopedia of Mathematics and Its Applications, Cambridge University Press, Cambridge, UK, 1989.

[15] F. Skof, "Local properties and approximation of operators," Rendiconti del Seminario Matematico e Fisico di Milano, vol. 53, pp. 113-129, 1983.

[16] P. W. Cholewa, "Remarks on the stability of functional equations," Aequationes Mathematicae, vol. 27, no. 1, pp. 76-86, 1984.

[17] S. Czerwik, "On the stability of the quadratic mapping in normed spaces," Abhandlungen aus dem Mathematischen Seminar der Universität Hamburg, vol. 62, pp. 59-64, 1992.

[18] J. Wang, "Some further generalizations of the Hyers-Ulam-Rassias stability of functional equations," Journal of Mathematical Analysis and Applications, vol. 263, no. 2, pp. 406-423, 2001.

[19] K.-W. Jun, J.-H. Bae, and Y.-H. Lee, "On the Hyers-Ulam-Rassias stability of an $n$-dimensional Pexiderized quadratic equation," Mathematical Inequalities \& Applications, vol. 7, no. 1, pp. 63-77, 2004.

[20] K.-W. Jun and H.-M. Kim, "On the stability of an $n$-dimensional quadratic and additive functional equation," Mathematical Inequalities \& Applications, vol. 9, no. 1, pp. 153-165, 2006.

[21] K.-W. Jun and Y.-H. Lee, "On the Hyers-Ulam-Rassias stability of a generalized quadratic equation," Bulletin of the Korean Mathematical Society, vol. 38, no. 2, pp. 261-272, 2001.

[22] K.-W. Jun and Y.-H. Lee, "On the Hyers-Ulam-Rassias stability of a Pexiderized quadratic inequality," Mathematical Inequalities \& Applications, vol. 4, no. 1, pp. 93-118, 2001. 